\section{Correlation of higher-order wavefront aberrations with visual function in pseudophakic eyes}

\begin{abstract}
Aim To study the correlation between higher-order wavefront aberrations and visual function in eyes with a spherical monofocal intraocular lens (IOL), and to see if the aberrations differ between eyes that received different types of IOLs.

Methods One hundred forty-eight eyes of 148 patients who underwent phacoemulsification and implantation of one of five types of acrylic IOL were enrolled. At 1 month after surgery, ocular aberrations were measured using a Hartmann-Shack aberrometer and corneal aberrations were measured using videokeratography. In addition, the aberration of internal optics was determined by subtracting the corneal aberration from the ocular aberration. These aberrations were correlated with visual acuity and with contrast visual acuity under both photopic and mesopic conditions.
\end{abstract}

${ }^{1}$ Hayashi Eye Hospital, Fukuoka, Japan

${ }^{2}$ Department of Ophthalmology, School of Medicine, Fukuoka University, Fukuoka, Japan

Correspondence: K Hayashi, Hayashi Eye Hospital, 4-7-13 Hakataekimae, Hakata-Ku,

Fukuoka 812, Japan

Tel: + 8192431 1680;

Fax: + 81924415303

E-mail: hayashi-ken@

hayashi.or.jp

Received: 2 February 2007 Accepted in revised form: 1 June 2007

Published online: 29 June 2007
Results Ocular, corneal, and internal optic aberrations (total aberration, coma, and spherical aberration) were all correlated significantly with visual acuity, as well as with photopic and mesopic contrast visual acuity. The associations between internal optic aberrations and visual function tended to be stronger than were those of corneal aberrations. Furthermore, ocular aberrations differed significantly between eyes with the five different IOLs $(P \leqslant 0.0078)$. Specifically, the internal optic spherical aberration was markedly significantly different between eyes $(P=0.0142)$, and the corneal coma showed a marginally significant difference $(P=\mathbf{0 . 0 4 2 1})$. Conclusion Ocular, corneal, and internal optic higher-order wavefront aberrations are correlated significantly with visual function in eyes with a spherical monofocal IOL. The spherical aberration of the internal optics and coma of the cornea vary between eyes with different types of IOL.

Eye (2008) 22, 1476-1482; doi:10.1038/sj.eye.6702921; published online 29 June 2007

Keywords: higher-order wavefront aberration; visual function; cataract surgery; spherical intraocular lens

Introduction

It has been shown in young subjects that higher-order positive spherical aberration of the anterior cornea is compensated for partially by a negative spherical-like aberration of the internal optics of the eye, which is predominantly the crystalline lens. ${ }^{1-3}$ However, spherical aberration of the crystalline lens increases with age, ${ }^{4}$ whereas the corneal aberration changes little throughout life. ${ }^{5,6}$ Therefore, the total ocular aberration increases with age, leading to deterioration of optical quality in older subjects. ${ }^{7-10}$ When the crystalline lens is replaced by an intraocular lens (IOL) in cataract surgery, further changes may occur. It has been shown that ocular higher-order aberration in pseudophakic eyes is comparable with that in phakic eyes of subjects of the same age. ${ }^{11-13}$ This is because standard IOLs have a positive spherical aberration, and thus add to the total ocular aberration.

Previous studies showed that many types of corneal refractive surgery increase the higher-order aberrations in proportion to the magnitude of refractive correction, and, accordingly, worsen contrast sensitivity. ${ }^{14-21}$ Furthermore, some studies demonstrated that the ocular or corneal aberration is correlated 
significantly with contrast sensitivity after corneal refractive surgery. ${ }^{22-24}$ Although some studies showed that contrast sensitivity in eyes with an aspherical IOL is better than that in eyes with a spherical IOL, ${ }^{25-29}$ to our knowledge, there has been no study to show the statistical association of higher-order aberrations with visual functions in eyes with a standard spherical IOL.

When the subtracted value of the corneal aberration from the ocular aberration is assumed to be the aberration caused by the internal optics, ${ }^{2,8}$ the internal optic aberration in pseudophakic eyes consists of that of the posterior corneal surface, ocular media, and IOL. ${ }^{8,12}$ However, because the posterior corneal surface and ocular media generally have little aberration, that derived from the IOL is thought to predominate in internal optic aberrations. Many experimental and several clinical studies have shown that IOLs have various degrees of higher-order aberration and optical quality depending on optic design, optic material, and dioptric power. ${ }^{12,13,29-35}$

The purpose of the study described herein was to investigate the correlation of higher-order aberrations with visual functions in eyes with a standard spherical monofocal IOL, and to confirm which types of higher-order aberration differ between eyes that received different types of IOLs.

\section{Materials and methods}

\section{Patients}

All patients who were sequentially scheduled for cataract surgery at the Hayashi Eye Hospital between October 2003 and February 2004 were screened for enrollment by a clinical research coordinator. Exclusion criteria were any pathology other than cataract, a history of ocular surgery or inflammation, eyes scheduled for extracapsular cataract extraction, pupillary diameter $<4.0 \mathrm{~mm}$, and eyes of diabetics. Patients who anticipated any difficulty with follow-up were also excluded.

One hundred seventy eyes of 170 patients who were to undergo phacoemulsification and IOL implantation were eligible for inclusion in this study. When both eyes were to undergo surgery, only the eye operated on first was included. The hospital's Institutional Review Board approved the study protocol, and all patients provided informed consent.

\section{Surgical technique}

All surgeries were performed by one of two surgeons ( $\mathrm{KH}$ and MY) using the same surgical procedure as that described previously. ${ }^{36}$ First, a 3.0 or $3.5 \mathrm{~mm}$ straight scleral incision was made for IOL implantation. After incision, a continuous curvilinear capsulorrhexis measuring approximately $5.0 \mathrm{~mm}$ in diameter was accomplished using a bent needle. After hydrodissection, endocapsular phacoemulsification of the nucleus and aspiration of the residual cortex were carried out. Using a steel keratome, the wound was enlarged to 3.0, 3.5, or $4.1 \mathrm{~mm}$ for IOL implantation. The lens capsule was inflated with sodium hyaluronate 1\% (Healon; Advanced Medical Optics (AMO), Santa Ana, CA, USA), after which the IOL was placed into the capsular bag using the forceps or injector. After insertion, the viscoelastic material was thoroughly evacuated. In this series, all surgeries were uneventful and all IOLs were implanted in the capsular bag. The IOLs used were MA60AC, MA50BM, SA60AT (Alcon Laboratories, Fort Worth, TX, USA), AR40e (AMO), and VA60BB (HOYA, Tokyo, Japan). The numbers of eyes that received each IOL were MA60AC in 55 eyes, MA50BM in 14, SA60AT in 24, AR40e in 42, and VA60BB in 13. The MA60AC, AR40e, and VA60BB have a $6.0 \mathrm{~mm}$ spherical acrylic optic with polymethyl methacrylate (PMMA) haptics. The MA50BM has a $6.5 \mathrm{~mm}$ spherical acrylic optic and PMMA haptics. The SA60AT is a single-piece acrylic IOL with a $6.0 \mathrm{~mm}$ spherical optic. The MA60AC, SA60AT, AR40e, and VA60BB have a biconvex but anteriorly more curved optic, whereas the MA50BM has a posteriorly more curved optic.

\section{Main outcome measures}

At approximately 1 month after surgery, all patients underwent examination of ocular and corneal higher-order aberrations, visual acuity, refractive status, pupillary diameter, and contrast visual acuity with and without a glare source. Ocular higher-order aberrations were measured using a Hartmann-Shack ocular aberrometer (KR-9000PW; Topcon, Tokyo, Japan), and corneal higher-order aberrations were measured using videokeratography (KR-9000PW). The KR-9000PW consists of a combination of a Hartmann-Shack ocular aberrometer and a Placido disk videokeratographer, and thus provides aberration values for the whole eye (ocular aberrations) and for the anterior corneal surface (corneal aberrations). Best-corrected visual acuity was determined using decimal charts, and was converted to a logarithm of minimal angle of resolution ( $\log$ MAR) scale for statistical analysis. The spherical and cylindrical refractive powers were measured using an autorefractometer (KR-7100; Topcon). Pupil diameter was measured using a Colvard pupillometer (Oasis Medical, Glendora, CA, USA). Contrast visual acuity under photopic and mesopic conditions was examined using the Contrast Sensitivity Accurate Tester (CAT-2000; Menicon, Tokyo, Japan). 
Ocular wavefront aberration and videokeratographic data on all patients were obtained using the Hartmann-Shack wavefront analyzer and computerized videokeratography apparatus, both of which are incorporated in the KR-9000PW. The details of this apparatus have been described previously. ${ }^{37}$

Measurements were taken of natural, undilated pupils, and were repeated at least three times in each eye to obtain a properly aligned image. The Hartmann-Shack aberrometer projects light onto the retina, and the light reflected from the retina passed through the internal oculus. The reflected light passes through the Hartmann plate and becomes a spot of light, which forms an image on a charge-coupled device camera. Displacement of the image formation is analysed as wavefront distortion. The higher-order wavefront aberrations (first to sixth order wavefront Zernike aberrations) were calculated from the displacement and were expanded with the Zernike polynomials.

As the mean value of the pupillary diameter in this series was $4.4 \mathrm{~mm}$, analysis of the higher-order aberration was conducted by measuring the central 4.0-mm with aperture. From the Zernike coefficients, coma-like aberrations (coma: third-order component $\left[S_{3}\right]$ ), spherical aberrations (fourth-order component $\left[S_{4}\right]$ ), and total higher-order aberrations (third- through sixth-order components) were calculated with the KR-9000PW program. For example, $S_{3}$ was defined as the root mean square of all four Zernike terms in third order. Computerized videokeratography was measured simultaneously using a Placido disk attached to the KR-9000PW, and corneal coma, spherical aberration, and total aberration were also calculated using Zernike polynomials. Furthermore, with assumption of a simple model for the eye, aberrations of the internal optics (internal optic aberrations) could be obtained by direct subtraction of the anterior corneal aberrations from the ocular aberrations. ${ }^{2,8,12}$

Contrast visual acuity was examined using the CAT-2000. ${ }^{38}$ This device measures $\log$ MAR visual acuity using five contrast visual targets $(100,25,10,5$, and $2.5 \%)$ under photopic and mesopic conditions. In this study, measurement under photopic conditions was carried out with chart lighting of $100 \mathrm{~cd} / \mathrm{m}^{2}$, and that under mesopic conditions with chart lighting of $5 \mathrm{~cd} / \mathrm{m}^{2}$. All measurements were performed by ophthalmic technicians who were unaware of the purpose of this study.

\section{Statistical analysis}

Associations between the higher-order aberrations and visual function and between ocular and corneal or internal optic aberrations were evaluated using simple correlation coefficients. The differences in these aberrations between eyes that received different types of IOL were tested using the Kruskal-Wallis test. Discrete variables were compared using the $\chi^{2}$ test. Any differences showing $P<0.05$ were considered to be statistically significant.

\section{Results}

Of the 566 patients screened for inclusion, 208 were not eligible according to the exclusion criteria, and another 188 patients declined to be enrolled. Accordingly, 170 patients were enrolled in this study. No significant difference was found in age $(P=0.4846)$ or gender $(P=0.6099)$ between the patients who were enrolled and those who were excluded. Of the 170 patients initially enrolled, 22 were excluded from the analysis: four did not appear for examination, two refused the examination, accurate data could not be obtained in nine, and pupillary diameter decreased to $<4.0 \mathrm{~mm}$ after cataract surgery in seven. ${ }^{39}$ Accordingly, 148 patients (87.1\%) completed the examination and their data remained in the analysis.

The average age of the patients $( \pm S D)$ was $69.7 \pm 8.5$ years, with a range of 39-88 years. There were 53 men and 95 women. The patient characteristics of the five IOL groups are shown in Table 1; no statistically significant differences were found in age, gender, ratio of left to right eyes, or pupillary diameter. The dioptric powers of the implanted IOLs tended to be different between the groups, but the difference did not reach statistical significance $(P=0.0659)$.

Figure 1 shows the mean $( \pm S D)$ ocular, corneal, and internal optic aberrations (total aberration, coma, and spherical aberration). The corneal aberrations were greater than were the internal optic aberrations.

Table 1 Patient characteristics of the five different intraocular lens (IOL) groups

\begin{tabular}{lcccccc}
\hline & \multicolumn{7}{c}{ Types of IOL } \\
\cline { 2 - 7 } & MA60AC & MA50BM & SA60AT & AR40e & VA60BB & P-value \\
\hline No. of eyes & 55 & 14 & 24 & 42 & 13 & - \\
Age (years) & 68.9 & 67.4 & 72.1 & 69.8 & 70.8 & $0.4279^{*}$ \\
Gender $^{\mathrm{a}}$ & $23 / 32$ & $6 / 11$ & $11 / 15$ & $12 / 31$ & $4 / 10$ & $0.5896^{*}$ \\
Left/right $^{\text {Pupil size }}$ & $29 / 26$ & $12 / 5$ & $14 / 12$ & $17 / 26$ & $7 / 7$ & $0.2845^{*}$ \\
IOL power $^{\mathrm{c}}$ & 4.6 & 4.6 & 4.3 & 4.3 & 4.3 & $0.1846^{*}$ \\
Interval $^{\mathrm{d}}$ & 18.9 & 18.9 & 20.3 & 20.3 & 21.8 & $0.0659^{*}$ \\
\hline
\end{tabular}

*No statistically significant difference.

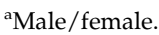

bPupillary diameter (mm)

'Diopteric power of the IOL (diopter)

${ }^{\mathrm{d}}$ Interval between cataract surgery and examination (days). 
However, although ocular total aberration, coma, and spherical aberration were correlated significantly with both corneal and internal optic aberrations, the associations between ocular and internal optic aberrations were stronger than were those between ocular and corneal aberrations (Table 2).

Table 3 shows the simple correlations between ocular, corneal, and internal optic aberrations (total aberration, coma, and spherical aberration) and corrected visual acuity, and photopic and mesopic contrast visual acuity. Ocular, corneal, and internal optic aberrations were all correlated significantly with corrected $\log$ MAR visual acuity, and photopic and mesopic contrast visual acuity. The correlation coefficients of internal optic aberrations with corrected visual acuity, contrast visual acuity, and glare visual acuity tended to be slightly greater than were those of corneal aberrations.

Comparison of the mean ocular, corneal, and internal optic aberrations (total aberration, coma, and spherical aberration) between eyes that received the five different types of IOL are shown in Figure $2 \mathrm{a}-\mathrm{c}$, respectively.

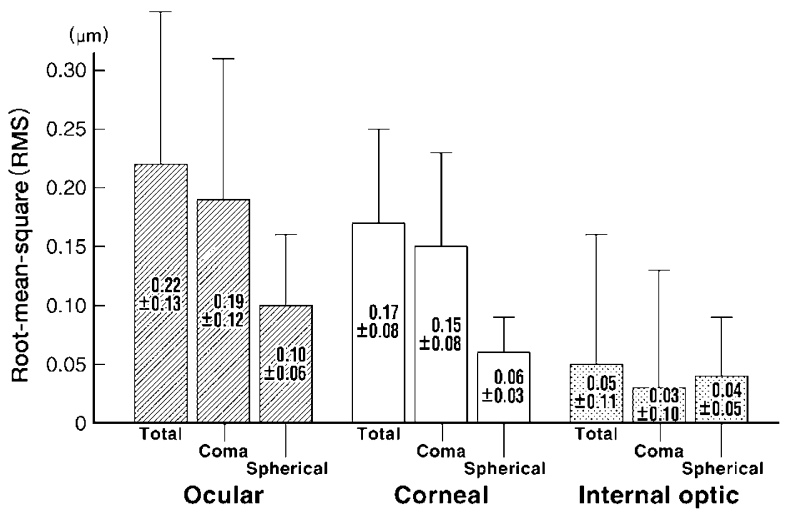

Figure 1 Mean $( \pm S D)$ ocular, corneal, and internal optic aberrations. Higher-order aberrations of the cornea were greater than were the internal optic aberrations.

Table 2 Simple correlation between ocular and corneal aberrations and between ocular and internal optic aberrations

\begin{tabular}{|c|c|c|}
\hline & Correlation coefficients $(\mathrm{r})$ & P-value \\
\hline \multicolumn{3}{|c|}{ Between ocular and corneal aberrations } \\
\hline Total & 0.572 & $<0.0001^{*}$ \\
\hline Coma & 0.543 & $<0.0001^{*}$ \\
\hline Spherical & 0.601 & $<0.0001^{*}$ \\
\hline \multicolumn{3}{|c|}{ Between ocular and internal optic aberrations } \\
\hline Total & 0.775 & $<0.0001^{*}$ \\
\hline Coma & 0.757 & $<0.0001^{*}$ \\
\hline Spherical & 0.835 & $<0.0001^{*}$ \\
\hline
\end{tabular}

*Statistically significant correlation.
The mean ocular total aberration, coma, and spherical aberration differed significantly between eyes with the different IOLs $(P \leqslant 0.0078)$. The differences in corneal

Table 3 Simple correlation between ocular, corneal, and internal optic aberrations and corrected visual acuity and photopic and mesopic contrast visual acuity

\begin{tabular}{|c|c|c|c|c|c|c|}
\hline & \multicolumn{2}{|r|}{ Total } & \multicolumn{2}{|c|}{$\operatorname{Coma}\left(S_{3}\right)$} & \multicolumn{2}{|c|}{ Spherical $\left(S_{4}\right)$} \\
\hline & $\mathrm{r}$ & P-value & $\mathrm{r}$ & P-value & $\mathrm{r}$ & P-value \\
\hline \multicolumn{7}{|c|}{ Ocular aberrations } \\
\hline Corrected $V$ & 0.435 & $<0.0001^{*}$ & 0.407 & $<0.0001^{*}$ & 0.425 & $<0.0001^{*}$ \\
\hline \multicolumn{7}{|c|}{ Photopic contrast VA } \\
\hline $100 \%$ & 0.453 & $<0.0001^{*}$ & 0.448 & $<0.0001^{*}$ & 0.347 & $<0.0001^{*}$ \\
\hline $25 \%$ & 0.507 & $<0.0001^{*}$ & 0.478 & $<0.0001^{*}$ & 0.484 & $<0.0001^{*}$ \\
\hline $10 \%$ & 0.448 & $<0.0001^{*}$ & 0.427 & $<0.0001^{*}$ & 0.414 & $<0.0001^{*}$ \\
\hline $5 \%$ & 0.462 & $<0.0001^{*}$ & 0.426 & $<0.0001^{*}$ & 0.450 & $<0.0001^{*}$ \\
\hline $2.5 \%$ & 0.173 & $0.0551^{\dagger}$ & 0.141 & $0.1208^{\dagger}$ & 0.185 & $0.0405^{*}$ \\
\hline \multicolumn{7}{|c|}{ Mesopic contrast VA } \\
\hline $100 \%$ & 0.344 & $<0.0001^{*}$ & 0.332 & $<0.0001^{*}$ & 0.310 & $0.0001^{*}$ \\
\hline $25 \%$ & 0.457 & $<0.0001^{*}$ & 0.437 & $<0.0001^{*}$ & 0.429 & $<0.0001^{*}$ \\
\hline $10 \%$ & 0.295 & $0.0004^{*}$ & 0.270 & $0.0011^{*}$ & 0.320 & $<0.0001^{*}$ \\
\hline $5 \%$ & 0.237 & $0.0096^{*}$ & 0.230 & $0.0118^{*}$ & 0.183 & $0.0467^{*}$ \\
\hline $2.5 \%$ & 0.348 & $0.0375^{*}$ & 0.330 & $0.0491^{*}$ & 0.201 & $0.2402^{\dagger}$ \\
\hline \multicolumn{7}{|c|}{ Corneal aberrations } \\
\hline Corrected $V$ & 0.339 & $<0.0001^{*}$ & 0.338 & $<0.0001^{*}$ & 0.208 & $0.0112^{*}$ \\
\hline \multicolumn{7}{|c|}{ Photopic contrast VA } \\
\hline $100 \%$ & 0.269 & $0.0010^{*}$ & 0.262 & $0.0014^{*}$ & 0.196 & $0.0172^{*}$ \\
\hline $25 \%$ & 0.336 & $<0.0001^{*}$ & 0.321 & $<0.0001^{*}$ & 0.306 & $0.0002^{*}$ \\
\hline $10 \%$ & 0.319 & $<0.0001^{*}$ & 0.305 & $0.0002^{*}$ & 0.262 & $0.0013^{*}$ \\
\hline $5 \%$ & 0.191 & $0.0241^{*}$ & 0.176 & $0.0376^{*}$ & 0.157 & $0.0639^{\dagger}$ \\
\hline $2.5 \%$ & 0.033 & $0.7177^{\dagger}$ & 0.056 & $0.5353^{\dagger}$ & 0.060 & $0.5131^{\dagger}$ \\
\hline \multicolumn{7}{|c|}{ Mesopic contrast VA } \\
\hline $100 \%$ & 0.281 & $0.0005^{*}$ & 0.280 & $0.0006^{*}$ & 0.155 & $0.0597^{\dagger}$ \\
\hline $25 \%$ & 0.276 & $0.0007^{*}$ & 0.275 & $0.0007^{*}$ & 0.184 & $0.0250^{*}$ \\
\hline $10 \%$ & 0.118 & $0.1608^{\dagger}$ & 0.106 & $0.2066^{\dagger}$ & 0.108 & $0.2006^{\dagger}$ \\
\hline $5 \%$ & 0.059 & $0.5254^{\dagger}$ & 0.049 & $0.5966^{\dagger}$ & 0.029 & $0.7577^{\dagger}$ \\
\hline $2.5 \%$ & 0.098 & $0.5705^{\dagger}$ & 0.118 & $0.4913^{\dagger}$ & 0.107 & $0.5350^{\dagger}$ \\
\hline
\end{tabular}

Internal optic aberrations

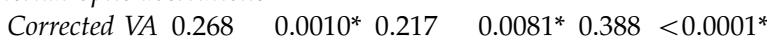

Photopic contrast VA

$100 \% \quad 0.344<0.0001^{*} 0.324<0.0001^{*} 0.298 \quad 0.0002^{*}$

$25 \% \quad 0.358<0.0001^{*} 0.313 \quad 0.0001^{*} 0.393<0.0001^{*}$

$10 \% \quad 0.300 \quad 0.0002 * 0.266 \quad 0.0011^{*} 0.336<0.0001 *$

$5 \% \quad 0.390<0.0001 * 0.346<0.0001 * 0.420<0.0001 *$

$\begin{array}{lllllll}2.5 \% & 0.214 & 0.0177^{*} 0.189 & 0.0363^{*} 0.176 & 0.0513^{\dagger}\end{array}$

Mesopic contrast VA

$\begin{array}{lllllll}100 \% & 0.202 & 0.0136^{*} & 0.174 & 0.0346^{*} & 0.280 & 0.0006^{*}\end{array}$

$25 \% \quad 0.344<0.0001 * 0.301 \quad 0.0002^{*} 0.409<0.0001^{*}$

$\begin{array}{llllll}10 \% & 0.250 & 0.0026^{*} 0.222 & 0.0077^{*} 0.302 & 0.0002^{*}\end{array}$

$\begin{array}{lllllll}5 \% & 0.192 & 0.0360 * & 0.179 & 0.0519 & 0.195 & 0.0333^{*}\end{array}$

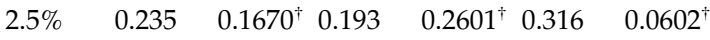

$\mathrm{VA}=$ visual acuity, $\%=$ percentage of contrast of visual target.

*Statistically significant correlation, ${ }^{\dagger}$ No significant correlation. 

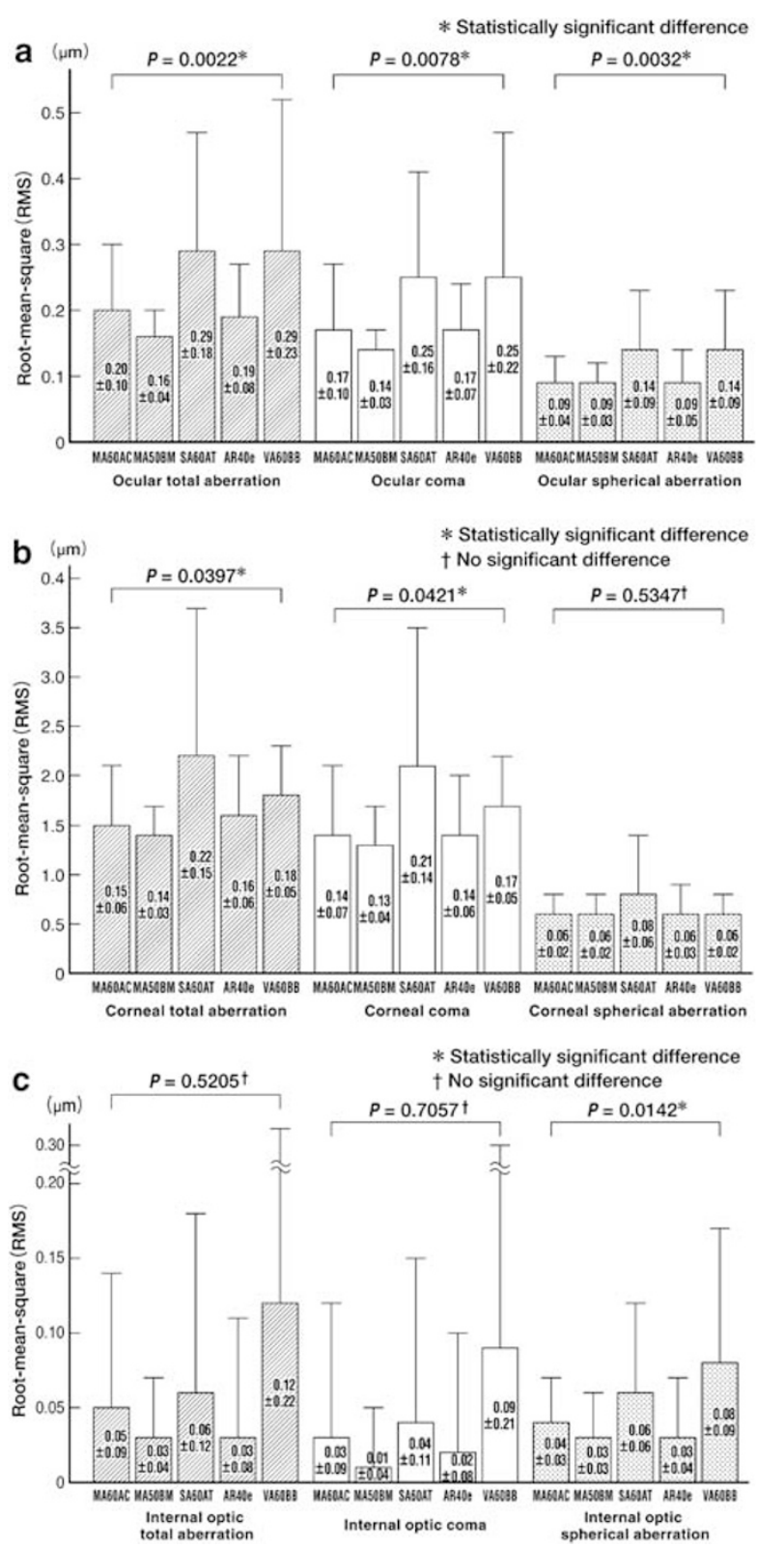

Figure 2 Comparisons of the mean $( \pm S D)$ ocular (a), corneal (b), and internal optic (c) aberrations between eyes that received the five different types of IOL. The mean ocular total aberration, coma, and spherical aberration differed significantly between the groups with different types of IOLs (a). The differences in corneal total aberration and coma were only marginally significant between groups (b), whereas the internal optic spherical aberration was markedly significantly different (c).

total aberration and coma were significant only marginally $(P \geqslant 0.0397)$, and there was no significant difference in corneal spherical aberration. The internal optic spherical aberration was significantly different between the groups $(P=0.0142)$, but there was no significant difference in internal optic total or coma.

\section{Discussion}

In our study, ocular, corneal, and internal optic higherorder aberrations (total aberration, coma, and spherical aberration) were all correlated significantly with visual acuity and contrast visual acuity in eyes with a standard spherical IOL. Although internal optic aberrations were smaller than were corneal aberrations, the association of internal optic aberrations with visual function tended to be stronger than that of corneal aberrations. These results suggest that higher-order aberrations of both the anterior cornea and the internal optics affect visual function following cataract surgery. In particular, aberrations of the internal optics, which consist primarily of the IOL, may be related more strongly to visual function than are corneal aberrations.

The ocular aberration was correlated significantly with both corneal and internal optic aberrations. However, the correlations between ocular and internal optic aberrations were stronger than that between ocular and corneal aberrations. Specifically, the correlation between spherical aberrations of the internal optics and the whole eye was quite strong. These results suggest that spherical aberrations of the internal optics, predominantly the IOL, may be important in higher-order aberrations in pseudophakic eyes.

Total aberration, coma, and spherical aberrations all differed significantly between eyes that received the different types of acrylic IOLs. Coma of the cornea was only marginally different, albeit significantly, between eyes with different types of IOLs, whereas corneal spherical aberrations were comparable. We have previously shown that a slight corneal asymmetry is induced in proportion to incision size even after small incision cataract surgery, ${ }^{40}$ and the cataract incision is therefore thought to cause coma of the cornea, which is in agreement with findings of other studies. ${ }^{12,13}$ These findings suggest that the slight difference in corneal coma observed in the present study might be due to variations in the size and design of the incision required for implantation of the five different IOLs.

More importantly, spherical aberration of the internal optics differed significantly between eyes with IOLs of different optic material and design. In addition, the dioptric powers of the implanted IOLs tended to differ depending upon the type of IOL, although this difference did not reach statistical significance. Experimental studies using several methods, including modulation transfer function, clarified that the optical quality of the IOL differs by optic design, optic material, and dioptres. ${ }^{29-32}$ Our clinical study also suggests that spherical aberration of the internal optics varies according to optic design, optic material, and possibly dioptric power of the implanted IOL. Furthermore, there 
are recent reports that marked tilt of the IOL causes coma, whereas IOL decentration does not have so marked an influence in the actual clinical situation. ${ }^{41-43}$ However, in this series, coma of internal optics did not differ between eyes with different IOLs, probably because the degree of tilt was not so extensive as to make a difference in coma.

Many previous studies showed that standard IOLs confer positive spherical aberration to the eye. ${ }^{12,13,29-35}$ It has been also shown that the higher-order aberration of pseudophakic eyes is comparable with that of phakic eyes of subjects of the same age, and is greater than that of young phakic eyes. ${ }^{11-13}$ Recently, to compensate for the positive spherical aberration of the cornea, a prolate IOL with negative spherical aberration, the so-called aspherical IOL, has been developed. Several studies showed that the higher-order aberration in eyes with this aspherical IOL was less than that in eyes with the standard spherical IOL, and that this lesser aberration led to better contrast sensitivity, particularly under mesopic conditions. ${ }^{25-28}$ However, although many studies have shown that the higher-order aberration is correlated significantly with contrast sensitivity after corneal refractive surgery, ${ }^{22-24}$ to our knowledge, no study has shown a statistically significant correlation between higher-order aberration and visual function in eyes with a standard spherical IOL. Our study has now clarified that a significant association between higher-order aberration and visual function after cataract surgery does exist.

We acknowledge that there is a limitation to the present study. The numbers of each type of the IOLs and the dioptres of the IOLs were not adjusted between the five different IOL groups. Therefore, although it is clear that the higher-order aberrations were different between eyes that received the different types of IOL, it is difficult to determine which type of IOL is best with regard to the higher-order aberrations. However, the gist of this study was not to find the IOL with the least aberration, but, rather, to confirm clinically the presence of a difference in higher-order aberration between IOLs. As many factors affect the higher-order aberrations of IOLs, a strictly designed comparative study is necessary.

In conclusion, the higher-order aberrations of the whole eye, cornea, and internal optics are all correlated significantly with the visual functions of eyes that received a standard spherical IOL. In particular, higherorder aberrations of the internal optics, aberrations that are derived predominantly from the IOL, may be important after cataract surgery. In addition, the spherical aberrations of the internal optics and the coma of the cornea were different between eyes that received the different types of IOLs. To obtain better quality of vision after cataract surgery, the surgeon should choose an IOL of appropriate optic design and material that will minimize the higher-order aberrations. In order to identify the best optic design and material for use in clinical situations, a strictly designed comparative study is necessary.

\section{Acknowledgements}

We have no proprietary interest in any of the materials mentioned in this article and received no financial support for the study described herein. This article has not published elsewhere.

\section{References}

1 Artal P, Guirao A. Contribution of the cornea and the lens to the aberrations of the human eye. Opt Lett 1998; 23: 1713-1715.

2 Artal P, Guirao A, Berrio E, Williams DR. Compensation of corneal aberrations by the internal optics in the human eye. $J$ Vis [serial online] 2001; 1: 1-8.

3 Kelly JE, Mihashi T, Howland HC. Compensation of corneal horizontal/vertical astigmatism, lateral coma, and spherical aberration by internal optics of the eye. J Vis [serial online] 2004; 4: 262-271.

4 Glasser A, Campbell MC. Presbyopia and the optical changes in the human crystalline lens with age. Vision Res 1998; 38: 209-229.

5 Guirao A, Redondo M, Artal P. Optical aberrations of the human cornea as a function of age. J Opt Soc Am A Opt Image Sci Vis 2000; 17: 1697-1702.

6 Oshika T, Klyce SD, Applegate RA, Howland HC. Changes in corneal wavefront aberrations with aging. Invest Ophthalmol Vis Sci 1999; 40: 1351-1355.

7 Calver RI, Cox MJ, Elliott DB. Effect of aging on the monochromatic aberrations of the human eye. J Opt Soc Am A Opt Image Sci Vis 1999; 16: 2069-2078.

8 Wang L, Koch DD. Ocular higher-order aberrations in individuals screened for refractive surgery. J Cataract Refract Surg 2003; 29: 1896-1903.

9 Artal P, Berrio E, Guirao A, Piers P. Contribution of the cornea and internal surfaces to the change of ocular aberrations with age. J Opt Soc Am A Opt Image Sci Vis 2002; 19: 137-143.

10 Amano S, Amano Y, Yamagami S, Miyai T, Miyata K, Samejima $\mathrm{T}$ et al. Age-related changes in corneal and ocular higher-order wavefront aberrations. Am J Ophthalmol 2004; 137: 988-992.

11 Guirao A, Redondo M, Geraghty E, Piers P, Norrby S, Artal P. Corneal optical aberrations and retinal image quality in patients in whom monofocal intraocular lenses were implanted. Arch Ophthalmol 2002; 120: 1143-1151.

12 Barbero S, Marcos S, Jimenez-Alfaro I. Optical aberrations of intraocular lenses measured in vivo and in vitro. J Opt Soc Am A Opt Image Sci Vis 2003; 20: 1841-1851.

13 Padmanabhan P, Yoon G, Porter J, Rao SK, Roy J, Choudhury M. Wavefront aberrations in eyes with Acrysof monofocal intraocular lenses. J Refract Surg 2006; 22: 237-242.

14 Applegate RA, Howland HC, Sharp RP, Cottingham AJ, Yee RW. Corneal aberrations and visual performance after radial keratectomy. J Refract Surg 1998; 14: 397-407. 
15 Holladay JT, Dudeja DR, Chang J. Functional vision and corneal changes after laser in situ keratomileusis determined by contrast sensitivity, glare testing, and corneal topography. J Cataracat Refract Surg 1999; 25: 663-669.

16 Oshika T, Klyce SD, Applegate RA, Howland HC, Danasoury MAE. Comparison of corneal wavefront aberrations after photorefractive keratectomy and laser in situ keratomileusis. Am J Ophthalmol 1999; 127: 1-7.

17 Marcos S. Aberrations and visual performance following standard laser vision correction. J Refract Surg 2001; 17: S596-S601.

18 Oshika T, Miyata K, Tokunaga T, Samejima T, Amano S, Tanaka $S$ et al. Higher order wavefront aberrations of cornea and magnitude of refractive correction in laser in situ keratomileusis. Ophthalmology 2002; 109: 1154-1158.

19 Ninomiya S, Maeda N, Kuroda T, Fujikado T, Tano Y. Comparison of ocular higher-order aberrations and visual performance between photorefractive keratectomy and laser in situ keratomileusis for myopia. Semin Ophthalmol 2003; 18: 29-34.

20 Ma L, Atchison DA, Albietz JM, Lenton LM, McLennan SG. Wavefront aberrations following laser in situ keratomileusis and refractive lens exchange for hypermetropia. J Refract Surg 2004; 20: 307-316.

21 Chandhrasri S, Knorz MC. Comparison of higher order aberrations and contrast sensitivity after LASIK, Verisyse phakic IOL, and Array multifocal IOL. J Refract Surg 2006; 22: 231-236.

22 Applegate RA, Hilmantel G, Howland HC, Tu EY, Starck T, Zayac EJ. Corneal first surface optical aberrations and visual performance. J Refract Surg 2000; 16: 507-514.

23 Yamane N, Miyata K, Samejima T, Hiraoka T, Kiuchi T, Okamoto $\mathrm{F}$ et al. Ocular higher-order aberrations and contrast sensitivity after conventional laser in situ keratomileusis. Invest Ophthalmol Vis Sci 2004; 45: 3986-3990.

24 Ueda T, Nawa Y, Masuda K, Ishibashi H, Hara Y, Uozato H. Relationship between corneal aberrations and contrast sensitivity after hyperopic laser in situ keratomileusis. Jpn J Ophthalmol 2006; 50: 147-152.

25 Packer M, Fine IH, Hoffman RS, Piers PA. Prospective randomized trial of an anterior surface modified prolate intraocular lens. J Refract Surg 2002; 18: 692-696.

26 Packer M, Fine IH, Hoffman RS, Piers PA. Improved functional vision with a modified prolate intraocular lens. J Cataract Refract Surg 2004; 30: 986-992.

27 Mester U, Dillinger P, Anterist N. Impact of a modified optic design on visual function: clinical comparative study. J Cataract Refract Surg 2003; 29: 652-660.

28 Kasper T, Buhren J, Kohnen T. Intraindividual comparison of higher-order aberrations after implantation of aspherical and spherical intraocular lenses as a function of pupil diameter. J Cataract Refract Surg 2006; 32: 78-84.

29 Rawer R, Stork W, Spraul CW, Lingenfelder C. Imaging quality of intraocular lenses. J Cataract Refract Surg 2005; 31: 1618-1631.

30 Atchison DA. Optical design of intraocular lenses. I. On-axis performance. Optom Vis Sci 1989; 66: 492-506.

31 Norrby NES, Grossman LW, Geraghty EP, Kreiner CF, Mihori M, Patel AS et al. Determining the imaging quality of intraocular lenses. J Cataract Refract Surg 1998; 24: 703-714.

32 Simpson MJ. Optical quality of intraocular lenses. J Cataract Refract Surg 1992; 18: 86-94.

33 Taketani F, Matsuura T, Yukawa E, Hara Y. High-order aberrations with Hydroview H60M and AcrySof MA30BA intraocular lenses: comparative study. J Cataract Refract Surg 2004; 30: 844-848.

34 Vilarrodona L, Barrett GD, Johnson B. High-order aberrations in pseudophakia with different intraocular lenses. I Cataract Refract Surg 2004; 30: 571-575.

35 Rocha KM, Chalita MR, Souza CEB, Soriano ES, Freitas LL, Muccioli $\mathrm{C}$ et al. Postoperative wavefront analysis and contrast sensitivity of a multifocal apodized diffractive IOL (ReSTOR) and three monofocal IOLs. J Refract Surg 2005; 21: S808-S812.

36 Hayashi K, Hayashi H. Intraocular lens factors that may affect anterior capsule contraction. Ophthalmology 2005; 112: 286-292.

37 Kuroda T, Fujikado T, Maeda N, Oshika T, Hirohara Y, Mihashi T. Wavefront analysis of higher-order aberrations in patients with cataract. J Cataract Refract Surg 2002; 28: 438-444.

38 Hayashi K, Hayashi H. Effect of a modified optic edge design on visual function: textured-edge versus round-anterior, slope-side edge. J Cataract Refract Surg 2004; 30: 1668-1674.

39 Hayashi K, Hayashi H. Pupil size before and after phacoemulsification in nondiabetic and diabetic patients. J Cataract Refract Surg 2004; 30: 2543-2550.

40 Hayashi K, Hayashi H, Oshika T, Hayashi F. Fourier analysis of irregular astigmatism after implantation of 3 types of intraocular lenses. J Cataract Refract Surg 2000; 26 1510-1516.

41 Taketani F, Matuura T, Yukawa E, Hara Y. Influence of intraocular lens tilt and decentration on wavefront aberrations. J Cataract Refract Surg 2004; 30: 2158-2162.

42 Taketani F, Yukawa E, Ueda T, Sugie Y, Kojima M, Hara Y. Effect of tilt of 2 acrylic intraocular lenses on high-order aberrations. J Cataract Refract Surg 2005; 31: 1182-1186.

43 Oshika T, Kawana K, Hiraoka T, Kaji Y, Kiuchi T. Ocular higher-order wavefront aberration caused by major tilting of intraocular lens. Am J Ophthalmol 2005; 140: 744-746. 